\title{
Evaluation of Agri-Environmental Measures in the Venice Lagoon Watershed. Expert Knowledge Elicitation and Multi-Criteria Analysis
}

\author{
Carlo Giupponi ${ }^{1,2 *}$, Anita Fassio ${ }^{2}$, Alessandra Sgobbi ${ }^{2}$ \\ ${ }^{1}$ Center for Environmental Economics and Management, Dipartimento di Scienze Economiche, \\ Università Ca' Foscari di Venezia \\ S. Giobbe 873, 30121 Venezia, Italy \\ ${ }^{2}$ Fondazione Eni Enrico Mattei \\ Corso Magenta 63, 20123 Milano, Italy
}

Received: 30 May 2008. Accepted: 27 August 2008.

\begin{abstract}
Various tools and approaches have been experimented worldwide to address the externalities arising from agricultural activities, among which the design of agri-environmental policies and the introduction of specific measures to cope with the environmental impacts of agricultural origin. The mechanisms adopted within the Common Agricultural Policy with such aim fall within the category of Agri-Environmental Schemes (AESs), which are market-based policy schemes aimed at providing farmers with the right incentives to adopt farming practices yielding positive environmental externalities and are based on voluntary participation.

Given the intrinsic complexity of agro-ecosystems and the effects of farmers' behaviour, the assessment of the effectiveness and cost-effectiveness of AESs is always challenging, and often both the environmental and economic role of AESs are questionable. The main objective of this paper is to present a framework for assessing the effectiveness of AESs in promoting social and environmental sustainability in Europe, based on experts' knowledge. Experts' knowledge, acquired through adequate elicitation strategies and managed with robust and transparent methodologies, can help building a system of information that can then be used to infer the effectiveness of agri-environmental measures, at least in comparative terms, if not in terms of quantitative absolute estimations. In the present study, the NetSyMoD framework approach has been adopted.

First, a short introduction of the policy evaluation framework, the role of monitoring and performance indicators and of experts' opinion is provided. Subsequently the methodology used to identify experts and to elicit their assessment on the effectiveness of AES schemes is presented. Finally, the paper provides a concrete example in which experts' opinions have been used for the assessment exercise, and presents a framework for collecting, managing and integrating different opinions with quantitative indicators.
\end{abstract}

Key-words: agri-environment, participatory modelling, expert knowledge multicriteria evaluation.

\section{Introduction}

Agricultural systems can generally be considered the result of alterations to natural ecosystems brought about by humans, the farmers, who plan and implement sequences of activities with the objective of maximising crop yields, under environmental and economic constraints. Farming practices alter biogeochemical cycles (e.g. by means of chemical fertiliser inputs), energy fluxes (e.g. with machinery operations), natural populations of plants (e.g. weeds), insects, etc. Some of these alterations produce negative impacts on the environment, like in the case of pollution phenomena caused by releases of pesticides in drainage water.

The main driver of farmers' behaviour is the market, as the primary objective is income maximisation, although varying degrees of risk aversion can also characterise farmers' decisions, including the consideration of strategies to preserve their natural capital and therefore the environment (e.g. erosion control practices). Unfortunately, practices to control environmental impacts in general are not supported by the

* Corresponding Author: Tel.: +39 041 2349126; Fax: +39 041 2349176. E-mail address: cgiupponi@unive.it. 
market and risk management strategies, in particular when there are no direct negative consequences for the farmers, like in the case of groundwater pollution by nitrates of agricultural origin.

The failure of markets to induce the internalisation of negative externalities of behaviour is exacerbated by the fact that many agricultural techniques that could be considered rational from technical and economic viewpoints may have direct or indirect negative impacts on environmental resources.

Various approaches have been experimented worldwide to address the minimisation of environmental impacts of agricultural activities, while sustaining those practices playing instead a positive role for environmental preservation, first of all, in Europe, agri-environmental policy measures, within the framework of the Common Agricultural Policy (CAP). In this context, agriculture in Europe is acknowledged to provide several environmental and social beneficial effects, within the broad concept of multifunctionality, and it is therefore considered appropriate to compensate those farmers who provide environmental services beyond the standards of good farming practices. The mechanisms adopted within the Common Agricultural Policy with such aim fall within the category of Agri-Environmental Schemes (AESs), which are marketbased policy schemes aimed at providing farmers with the right incentives to adopt farming practices yielding positive environmental services and are based on voluntary participation.

Many different AESs have been introduced in EU Member States over the last few decades, for instance payments to compensate farmers for the expected reductions in yields as a consequence of adopting more environmentally friendly fertilisation practices.

Given the intrinsic complexity of agroecosystems and the effects of farmers' behaviour, the assessment of the effectiveness and cost-effectiveness of - alternative - AESs is always challenging, and often both environmental and economic effectiveness of AESs are questionable. A clear understanding of theses issues requires an integrated analysis of farmers' behaviour, institutional arrangements and environmental impacts. The present work originates in the European Research project ITAES (Integrated Tools to design and implement Agro
Environmental Schemes), aimed at identifyng factors that affect the effectiveness of AESS and provide suggestions for their optimal design, and focuses in particular on the potentials of expert knowledge elicitation techniques.

In recent years, the evaluation of agri-environmental policies, and specifically of AESs, has emerged as an issue of great relevance, not only for obvious ethical reasons, given that they are financed by taxpayers, but also because they are specifically required by the European legislation.

Three main types of assessment are of interest within the issue of agricultural policy evaluation: ex ante (i.e. before policy implementation) and ex post (i.e. a given time after the application of AESs), with an intermediate case in itinere (i.e. during the application period of a given programme). Ex ante evaluation refers to the forward-looking assessments of the likely future effects (environmental impacts) of new policies or proposals. This work can be done through the use of models and development of scenarios. Ex post evaluation relies on the collection of information about what has actually happened following the introduction of a particular measure, thereby establishing the actual effects of the policy instrument and allowing the comparison of the relative effectiveness of different measures in meeting their objectives, as well as their relative cost-effectivess. Ex post evaluations can provide feedback information for policy-makers about the actual impact of a measure. Results can be used to construct and calibrate evidence-based models and to underpin ex ante evaluation. Finally, the in itinere assessment refers to the evaluation of AESs during the course of their implementation, and is aimed at increasing the flexibility of the tools used, by allowing the integration of lessons learned, the implementation of mitigation measures for unforeseen impacts, or the correction of identified obstacles.

The main objective of this paper is to present a framework for assessing the effectiveness of AESs based on robust methods for the elicitation and management of experts' knowledge. In the following sections firstly a short introduction of the policy evaluation framework, the role of monitoring and performance indicators, and of experts' opinion is provided. Secondly, the methodology used to identify experts and to 
elicit their assessment on the effectiveness of AES schemes is presented. Finally, the paper provides a concrete example in which experts' opinions have been used for the assessment exercise, and presents a framework for collecting, managing and integrating different opinions in a coherent framework and with quantitative indicators.

\section{Background}

\subsection{Policy evaluation framework}

Evaluating the effects of a policy measure requires assessing the causal links between the measure and its ultimate environmental impact. The results of the evaluation should be presented in a way comprehensible to a wider public of stakeholders and policy makers. For that purpose further analysis may be required, to derive synthetic evaluation indices, which could be obtained, for instance, by applying Multiple Criteria Analysis (MCA) methods or similar approaches (Hwang and Yoon, 1981).

Figure 1 illustrates how the effects and effectiveness of policy measures fit into a wider policy evaluation framework, which seeks to answer a broader set of evaluative questions. The figure unpacks the relationships between societal needs, the policies issued, and their ultimate impacts into a number of key elements. The logic expressed by the framework depicted in Fig- ure 1 shows how policy measures should be determined in order to fulfil a specific need which relates to a range of issues (social, economic, environmental). Such measures are defined upon explicitly stated objectives or key purposes. Inputs are provided in terms of resources dedicated to the design and implementation of the measure that has a first tangible result, which is that of the performance in terms of adoption by the target group (outputs/results). The effects of these changes in behaviour on the specific environment are the outcomes of the measure (they are related to the more direct and immediate interaction with the environment) and on a more global scale, the ultimate effect (on the environment and therefore on human health) is identified as the impact of the policy (EEA, 2001).

The most important elements of the framework for the purposes of the present work are:

- Inputs: the resources dedicated to the design and implementation of a measure (e.g. the amount of subsidies and human resources in the competent administration).

- Performances: the first tangible results of a measure, which are obtained in exchange for public expenditure (e.g. degree of adoption by farmers).

- Outcomes: the response of the targeted system in terms of behavioural change (e.g. reductions of fertilisers' rates per hectare).

- Impacts: the ultimate effect of the induced

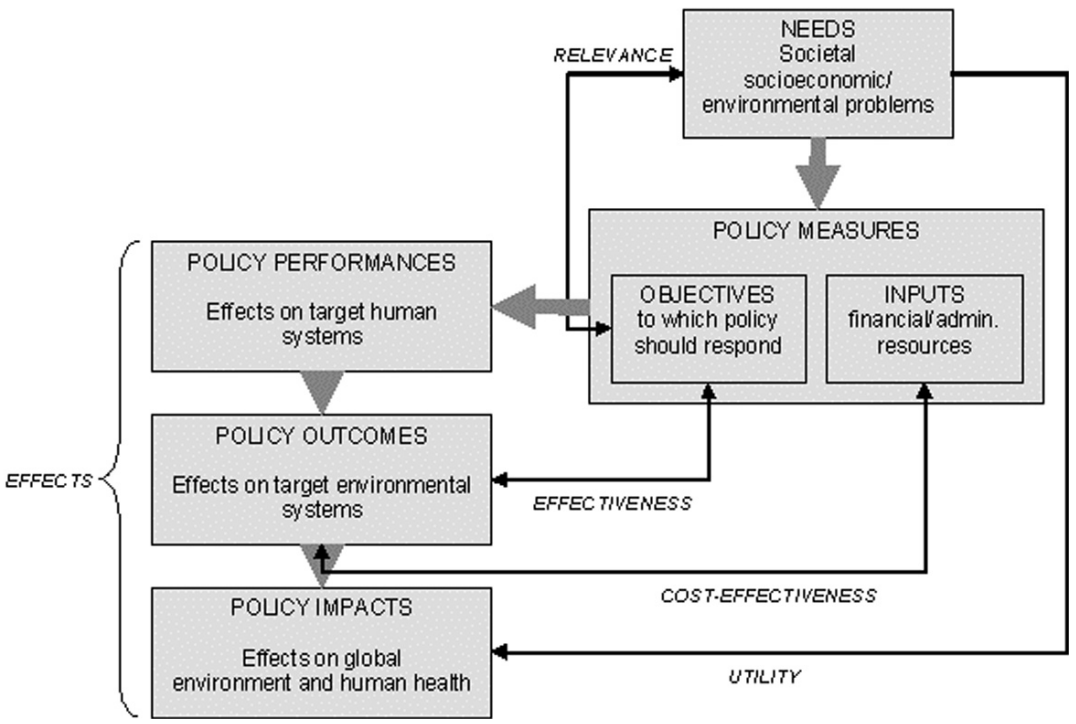

Figure 1. Evaluation framework for assessing the effectiveness, cost-effectiveness and utility of environmental measures (modified from EEA, 2001). 
behavioural changes on the environment and human health (e.g. reductions in emissions from cultivated fields).

The collection of information related to each of these categories allows various evaluations related to the implementation of a particular measure.

The effects of an environmental measure are the results that can be directly attributed to its implementation. By comparing the inputs with the results or outcomes, an assessment can be made of the cost-effectiveness of the measure; while, by comparing the effects with the intended objectives or reference thresholds, the effectiveness of the measure can be assessed, which is the main focus of this work. How these effects contribute to the overall needs of society can be further analysed in terms of welfare changes (utility) induced by the implemented measures - net of the implementation costs.

There are several factors which can provide insights into how to select the most appropriate policy evaluation methodology, such as (EEA, 2001):

- where links are few and predictable, standard models may be derived from examining case studies. These can be used as a broad basis for making more precise projections and for assessing the effects of different policy scenarios;

- where implementation chains are long and policy players are numerous, more specific empirical data need to be collected;

- where the application of a measure is differentiated geographically or by target sector, comparative case studies may be used to help identify relationships;

- where a target sector is relatively small the effects of measures may be established by indepth interviews;

- where the link between a policy and its impact on the environment is too diffuse or extended (e.g. general measures that establish procedures only), it may not be possible to evaluate the ultimate impacts of the measure on the environment. It may be more practical to focus an evaluation on immediate outputs and outcomes as a rough proxy for impact.

All the evaluation methods and approaches require the evaluators to establish an effective communication strategy to disseminate the re- sults of the assessment exercise, and ensure improvements in the design or implementation of the policy measures. Assessment indicators and indices are widely recognised as useful instruments to, on the one hand, facilitate the policy assessment exercise - be it ex ante, in itinere, or ex post - and, on the other hand, communicate the results in an easily understandable and useful format to both policy makers and stakeholders.

\subsection{Indicators and criteria}

The OECD (1997) defines three major desirable functions of environmental indicators in agriculture. Firstly, they should provide information to policy makers and the general public about the state of the environment influenced by agriculture. Secondly, they have to help policy makers to better understand the cause-effect loops between agricultural activities and the state of the environment. Thirdly, they have to assist in the evaluation of the effectiveness of agri-environmental policy instruments. These major functions can be performed only if the chosen set of indicators is framed within a conceptual framework that facilitates the work of policy makers in investigating the cause-effect loops, and in evaluating the effectiveness of the policy instrument.

In the present context, indicators are needed to quantify the elements of the policy evaluation framework, and tracing the policy process. Two main categories can be identified, according to the scheme described in Figure 1 and to the EC Working Document on Common Indicators for Monitoring Rural Development Programming (EC, 2005): firstly, monitoring indicators - and in particular the input (or resource) and output (or performance) indicators - enable operators to report on the use of resources allocated for the design and implementation of a policy, as well as on the activities for which they are fully responsible in terms of effects on the targeted human system ${ }^{1}$. Secondly, evaluation indicators go one step further monitoring, reporting and auditing, by providing an analysis of the effectiveness of the schemes in

\footnotetext{
1 Monitoring and evaluation of rural development programmes. http://europa.eu.int/comm/agriculture/rur/eval/index_en.htm
} 
terms of outcomes and impacts. Information provided by monitoring indicators can serve as a basis for evaluation.

Having defined the general framework for the assessment of the environmental effectiveness of policy measures and of AESs in particular, the problem emerges of identifying an adequate set of indicators for policy assessment, and defining how they should be used to derive evaluation criteria. The document with common evaluation indicators for the evaluation of rural development programmes is a key reference with this respect (EC, 2005).

Indicators need to be framed within a welldefined conceptual framework, allowing a clear understanding of the system of reference, and providing means for effective communication with policy makers. Therefore, a rather simplified communication approach is needed, able to trace, through the use of indicators, the causal links between human activities (agricultural production systems), and their ultimate impacts on the environment (e.g. water quality) and society in general (e.g. health, nutrition). The DPSIR (Driving force - Pressure - State - Impact - Response) environmental reporting framework proposed by the European Environmental Agency (1999) is widely used for similar purposes.

The DPSIR framework leads on from performances in terms of human behaviour to the consequences for the biophysical environment (outcomes/impacts). It also emphasises the importance of tracing through the causality of effects, thus linking the effects of a driving force (e.g. agricultural activities) to a certain pressure (e.g. nitrogen surpluses) to a change in the state of the natural resource (e.g. depletion of water quality) to a final impact (e.g. eutrophication of water bodies).

Thus, in order to evaluate the effects of a policy measure (i.e. a response in the DPSIR terminology), we need to trace through the strength of the arrows linking the different DPSIR elements, as well as tracing the policy process chain of performances to impacts (CEC, 2000).

At the centre of the framework is the current State of the agricultural environment and how this has changed over time. State indicators bring to the fore any undesirable changes which need to be combated (for example, nitrate or pesticide concentrations in water) as well as particularly desirable states which should be preserved (for example, the diversity of agricultural landscapes or valuable habitats) (CEC, 2000).

The second step is to identify the Pressures which have brought about undesirable changes or environmental benefits resulting from farming which have helped to preserve or enhance the environment. These have a negative and positive Impact, respectively, on the environment. The third step is to link these pressures and processes to the Driving Forces of the economy that are directly influenced by agricultural policy (i.e. farmers' activities), and it is here where the integration process is applied (CEC, 2000).

Finally, are agri-environmental measures (Responses) having the desired effect, are they responding quickly enough, or are they producing unforeseen problems?

The DPSIR framework allows the relevant questions to be posed, and identifies the information needed to answer these questions, i.e. the indicators. The next paragraph will elaborate on this point.

Understanding the nature of the links among all the elements in the DPSIR is of key importance in analysing the causes, intensity and consequences of environmental problems, as well as the effects and effectiveness of the policy responses designed to address them.

Regarding the effects of policy responses, once the main features of the socio-ecosystem of interest are known, the problem is usually defined in terms of estimating the effects of one or more response on the whole system, i.e. in terms of variations of the $\mathrm{D}, \mathrm{P}, \mathrm{S}$, and I indicators. This requires in theory a model which integrates the various components (social, environmental, etc.) in a dynamic simulator. Such a dynamic model is rarely available or designed, but at least a model intended as a mental representation of the system's behaviour is needed, in order to estimate the variations of indicator values expressing the effect of the response to be implemented. Here the techniques for experts' knowledge elicitation can provide operational solutions to the problem.

\subsection{The role of experts}

The ideal AESs evaluation should be based on both performance and outcome measurements 
to be used for the quantification of indicators and evaluation criteria. The former reveal possible problems in the policy implementation process, whereas the latter inform about the appropriateness of the policy design and of the impact model on which the design is based (Primdahl et al., 2002).

As stated above, calculating the effectiveness of a measure requires establishing a model of causal links between the measure and its ultimate impacts on the environment, but also on relevant socio-economic variables. In order to do this, it is essential to trace the link between the performances and outcomes of the measure and its potential impacts. For this reason it is necessary not only to collect data and identify suitable indicators of performances and outcomes of the measure, but also to categorise those indicators in a causal framework and to develop dynamic assessment procedures, based upon conceptual models providing explicit formalisations of the cause-effects relationships.

The formalisation of the agricultural system and its driving forces in a conceptual model should be considered as a prerequisite of the evaluation exercise, since it provides the knowledge about the causal chains among the various components of the system, and, in particular, the links between policy measures and their expected outcomes.

Finally, with a clear assessment model in mind, agri-environmental indicators can be theoretically measured in different ways:

- Ecological monitoring.

- Empirical or mechanistic modelling.

- Farm surveys.

- Local experts' opinion.

The feasibility of the first three approaches is often limited by various constraints, such as lack of data, of financial resources, limited time. This drives the attention on the use of experts' opinions for the evaluation of the efficiency and effectiveness of AESs, in order to fill the gaps in systematic scientific evidences. It is however clear that experts' opinions cannot be informally collected and collated, as the knowledge gathered should later be integrated with other quantitative data, and translated into a coherent set of evaluation indicators, a prerequisite for the application of evaluation methods such as MCAM.

The main issue at this stage is therefore the definition of a theoretically robust and practically feasible methodology to integrate experts' knowledge in a robust and transparent evaluation framework.

\section{Methods}

\subsection{The NetSyMoD approach for the elicitation of experts' knowledge}

NetSyMoD stands for Network Analysis - Creative System Modelling - Decision Support. The NetSyMoD ${ }^{2}$ methodology represents the result of several years of research at FEEM, Natural Resources Management Research Programme, in the field of environmental evaluations and decision-making. It has been designed as a flexible but comprehensive methodological framework which uses a suite of methods and support tools, aimed at facilitating the involvement of stakeholders or experts in environmental decision-making processes, in particular in those decision-making or evaluation processes characterised by the participation of multiple actors, typical in the field of environmental sciences. In such context, decisions and evaluations are intended in a broad sense to include any process in which a choice or a judgement has to be taken by examining the available information on a given problem. The problem itself, the information, the choice set and the judgement are defined with the contribution of different actors, who may be various experts in the relevant disciplines for the solution of a certain problem, or they may be the stakeholders and decision makers that are formally or informally involved in decision-making, for instance during the definition of a local development plan.

The main emphasis is on the integration and implementation, within the NetSyMoD framework, of state-of-the-art approaches in the field of modelling: from the more traditional approaches of bringing simulation models in the decision process through the development of $a d$ hoc decision support systems, to the more innovative creative thinking approaches for participative modelling design.

In the first phase the - iterative - identifi-

\footnotetext{
${ }^{2}$ More information on the NetSyMoD approach can be found on http://www.netsymod.eu/.
} 
cation of actors (stakeholders, experts...) to be involved is carried out, and their reciprocal relationships within the social network assessed. Once a sort of community of interested parties has been formed, mental modelling and techniques in the field of cognitive mapping are applied to analyse the problem, and to produce a shared conceptual model (i.e. a simplified representation of the part of the reality of interest). In other words, a formal description of the system and its causal links (as described above) is built in such a way that it can be easily understood and recognised by the actors involved in its development. The systems of interest for the proposed approach are those in which human activities interact with each other and with the natural resources.

The final phase of decision support may be of several natures, from cases in which group decision-making techniques are applied for supporting choices from a given set of alternative options, to others in which the opinions of experts have to find a common ground in the debate about a specific problem.

\subsection{The identification of experts}

The approach proposed in this paper aims at being flexible enough to be applied in different contexts and at different scales; it is designed to reduce the risks of omitting important actors in the evaluation process, and to ensure that their opinions are elicited in a transparent and robust manner, as well as integrated within a common framework. The approach suggested for involving experts is described in the remainder of the paper, with reference to a specific case study.

The first step of the identification process is suggested by different sources ${ }^{3}$ and it consists in forming an ad hoc steering group, hereafter referred to as task force group (TFG), involving a small number of people. The first task of the group is to take part in a brainstorming workshop aimed at drafting a list of the experts to be involved and at compiling their profiles according to a predefined set of categories. A team approach is likely to be more effective than an individual doing the identification process alone. In fact, a team can compensate for, and neutralise, individual biases. It can provide a more objective perspective of stakeholders/experts position and interests (Varvasosovsvszky and Brugha, 2000). The TFG should be composed by:
- a core group of experts: people who have a sound expertise in the subject under consideration, and a role to play in the evaluation exercise;

- one facilitator: this person should support the group and analyse the outcomes.

The ideal number of TFG members should be determined on a case-by-case basis, even though for the sake of meeting management efficiency it is advisable not to involve a large number of participants (i.e. less than ten, in general).

The first objective of the meeting is to clearly define the issue at stake (i.e. the specific interest within the broad context of AESs appraisal). The second step is to provide the TFG with a set of criteria for drafting the list of experts to be involved in the policy assessment. The set of criteria (ad hoc boundaries) has to be defined beforehand by the research team.

As far as the experts are concerned, the $a d$ hoc boundaries defined for their identification should depend on several factors, such as the scale of the investigation, the specific issue, etc. It is always good practice, however, to include a good mix of experts with a strong scientific background and with sound empirical knowledge.

The identified experts will then take part in a group assessment exercise/workshop. On the practical side, one needs to bear in mind that finding a suitable date for the meeting may be time-consuming, and this factor is worth considering when planning for the consultation process - in particular with experts. Moreover, researchers should be aware of the potential competition existing among experts: this should be kept to a minimum, in order to avoid a situation in which experts are not willing to speak their mind in front of people whom they perceive as competitors. If this appears to be an issue in the local context, Social Network Analysis (Wasserman and Faust, 1994; Wetherell et al., 1994) - usually adopted when a broad community of stakeholders has to be involved - will help minimise and manage this risk. Social Network Analysis entails building a network of the

\footnotetext{
3 E.g. Varvasosovsvszky and Brugha, 2000; Kossoudji, 2001; EC, 2003.
} 
community of experts with an interest in the problem under investigation, or with the potential to influence decisions or their implementation. In the case of experts' consultation, network relations can be constructed through a desk review, on two accounts: (i) history of collaboration among the experts identified by the TFG through, e.g., searches in international journal databases to identify authors and co-authorships, as well as cross-citations, or memberships in commissions, professional registers, consultancy work, etc. and (ii) by clustering experts' expressed views and expertise, with the purpose of carefully selecting participants representing views as well as fields and disciplines, and avoiding the participation of experts with similar views.

Whenever the boundaries of the population are not clear-cut or easy to impose using a set of identified criteria, a snowball sampling methodology can be adopted. This technique can be used to complete and improve the reliability of the first draft list, ensuring that all the relevant experts have been included. The sampling process begins when the research team selects a small number of participants, the socalled "seeds", who are the first to be involved in the process. These seeds should suggest other actors to be involved. The basic idea behind this kind of method is that respondents are not selected from a sampling frame, but from the linked network of existing members of the sample. This sampling process continues until the research team is reasonably sure that all the main actors have been identified (Salganik and Heckathorn, 2004).

The results of the experts identification phase and the following Social Network Analysis (when needed) should allow the identification of the key actors to be involved in the subsequent Creative System Modelling workshop, and they will also provide useful information for identifying the power relationships, the interest groups, and the main conflicts within the network of actors. A comprehensive flow-chart of the proposed framework can be found in Figure 2 .

\subsection{Creative thinking and modelling techniques for knowledge elicitation}

Creative System Modelling (CSM) is a key component of the NetSyMoD approach, that makes

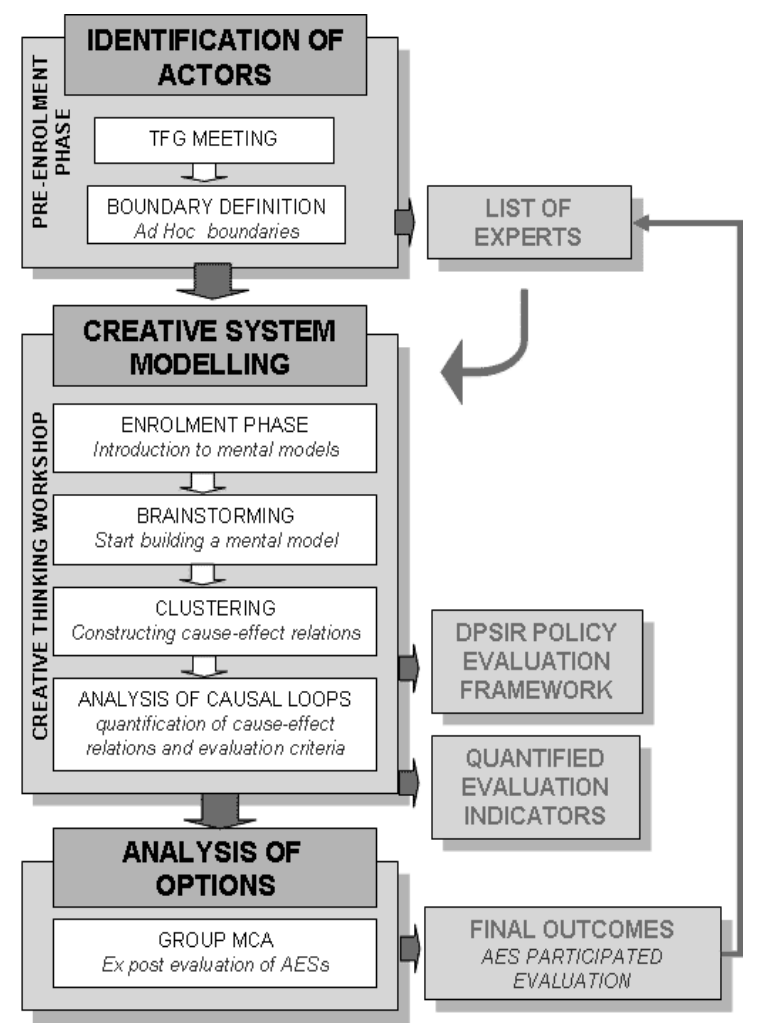

Figure 2. The NetSyMod approach for the environmental appraisal of AESs in the ITAES Project.

use of the outcomes of the Actors Identification and, when relevant, of the Social Network Analysis steps in order to give inputs to the final phase of evaluation.

In this field, the international literature is rich and diverse, although there is no clear agreement on terminology, methodologies, and so on and so forth. There are several reasons for this, such as the relative novelty of the topic and its development in rather distinct research fields (psychology, operation research, physics, natural sciences). Thus, one of the first concepts to be defined is that of mental models as distinguished from the usually adopted concept of model, which implicitly refers to the mathematical formalisation of real world systems for simulation exercises. There are many assumptions about mental models, and, even though the literature addressing this concept in various scientific fields is vast, the explicit definitions are quite rare. What emerges from the literature concerning mental models is that researchers and practitioners employ, to a degree, 
different techniques for eliciting and mapping mental models, which are based on their own unique definitions. A review of the literature dealing with the definitions of mental models was done by Doyle and Ford (1998), who concentrate on the definitions within the system dynamics and related system thinking literature, thus relevant in the present context. The authors offer a conceptual definition of mental models of dynamic systems: "A mental model of a dynamic system is a relatively enduring and accessible (conscious), but limited (not too complex to help decision making), internal, conceptual representation (cognitive structure not a process $^{4}$ ) of an external system ${ }^{5}$ whose structure maintains the perceived structure of that system". Thus a mental model exists in mind, and an external representation of an internal model is a cognitive map (Axelrod, 1976; Eden, 1994).

Cognitive Mapping (CM) is a general term that applies to a series of methods for providing external representations of mental models, functional to the further development of simulation models. Most researchers treat cognitive maps as a tool that can usefully summarise and communicate information, rather than as a literal description of mental images (Huff, 1990). Cognitive mapping was described by Downs and Stea (1973) as a process composed of a series of psychological transformations by which an individual acquires, codes, stores, recalls, and decodes information about the relative locations and attributes of phenomena in their everyday spatial environment.

In this context, $\mathrm{CM}$ provides a means for facilitating the process of participatory modelling and, more specifically, for eliciting knowledge and preferences from actors. CM techniques aim to provide a tool for revealing people's subjective beliefs in a meaningful way, usually expressed as networks of nodes connected by causal links. They are useful to gain insights into the problem from different perspectives, and this may then facilitate the evaluation process by identifying divergences and convergences, as well as encouraging negotiations and helping to reduce conflicts.

The key experts selected in the previous steps of the NetSyMoD approach take part in a workshop where, with the help of a professional facilitator, they apply the CM technique most suitable for the specific case. Although many alternative approaches are available, when dealing with experts for the elicitation of cognitive maps, techniques based on the Hodgson's hexagons approach (Hogdson, 1992) can be utilised. This approach allows an interactive creation of scenarios and alternatives, or, as in the case of AES assessment, the identification of the elements to be considered for the evaluation and the visions of the experts about the AESs to be evaluated. This technique is relatively simple and can be supported by the use of a specific software ${ }^{6}$.

The experts' workshop is organised in several phases. In the enrolment phase, the facilitator explains the CM exercise idea and its goals, and introduces participants to the workshop technique by interactive games. During the brainstorming, individuals contribute ideas through a semi-structured, open discussion, initiated by open questions projected with a beamer on a screen, and providing blank hexagons to be filled with the statements of the experts. Once all participants' perceptions are collected, the concepts are roughly clustered by the facilitator and shown back to the group. Further comments are integrated as participants review one another's contributions and piggy-back on one another's ideas in a plenary session. Linking concepts and building causal loops for further evaluation is exploited to initiate discussion around causes and effects, and to come to a shared understanding of the problem. Open questions and the following phases are designed in order to have, in the end, the DPSIR framework as a sort of standardised approach to a shared conceptual model about the problem at hand.

The CSM as described above can provide the common view of the causal links between the measures and the objectives. Such common view being shared at the workshop by all the experts

\footnotetext{
${ }^{4}$ Cognitive structures store information whereas cognitive processes are the mental operations that transform, elaborate, and reduce this information during decision making or problem solving.

${ }^{5}$ Mental model that refers to the one's own internal cognitive structure is named metamodel.

${ }^{6}$ Creative Thinker. For more information about the software see at http://www.cul.co.uk/software/rev3.htm.
} 
will subsequently serve as a basis for the quantification of causal loops, i.e. the identification and assessment of indicators, which is the final outcome of the CSM workshop, to be further elaborated in the multi-criteria analysis.

The association of quantitative indices to a closed list of possible answers allows the calculation of an "Environmental Effectiveness Index" (Finn and Kurz, 2004), as a combination of a series of indicators, i.e. criterion values within an MCA scheme. For that purpose, experts should also be asked to assign weights to each category of impact contained in the Environmental Effectiveness Index, that reflect political or other types of priorities. In practice, once the general evaluation of the AESs has been carried out, the experts are involved in the quantification of the indicators to be utilised later in the multi-criteria analysis. This can be done by means of an ad hoc questionnaire.

The CSM workshop has been designed to be last one day: approximately 3 hours in the morning for the Enrolment phase, Brainstorming and Clustering and 2-3 hours in the afternoon for the Analysis of causal loops through the compilation of a matrix. Alternatively, the latter phase could be carried out by the experts independently and, in this case, the workshop should last 3-4 hours (e.g. morning and social lunch).

The report on the Venice Lagoon Watershed case study summarised below will bring more concrete insight into how the NetSyMoD approach can be applied for AESs evaluation exercises.

\section{Case study: AES evaluation in the Venice La- goon Watershed}

\subsection{The case study}

The Venice Lagoon Watershed (VLW) is the portion of the alluvial plain of the Veneto Region (north-eastern Italy) that discharges into the Lagoon of Venice (Fig. 3). It has a surface area of around $1,850 \mathrm{~km}^{2}$, comprising $115 \mathrm{mu}-$ nicipalities and around one million inhabitants. The VLW is almost entirely flat and is characterised by a very complex hydrography, with rivers and artificial canals and 27 outlets in total.

The VLW is considered by the national legislation a sensitive area for the protection of water against pollution (D.Lgs. n. 152/99).

The land use is distributed as follows: $75 \%$ rural land (65\% cultivated lands), $15 \%$ urban and $5 \%$ industrial, the remaining $5 \%$ comprises vegetated areas, touristy infrastructure, urban parks, etc. The predominant crop is maize which is grown in over $56 \%$ of the cultivated lands. According to census data, about 210,000 bovines

Figure 3. The Venice Lagoon

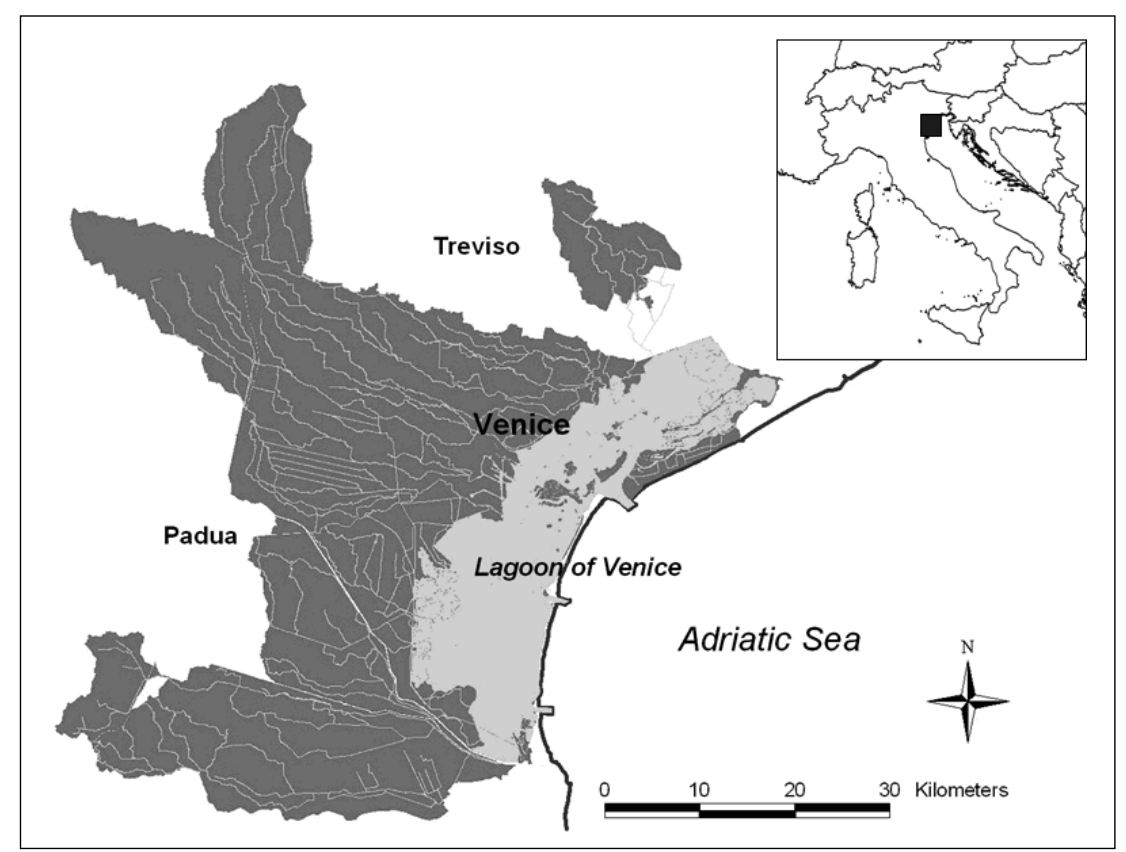


and 130,000 swine are reared in the VLW. Agriculture has a high input of fertilisation and the livestock production is intensive and scarcely integrated with crop production. During the 1980's and the early 1990's, high nutrient loads in the VLW have been responsible for a severe eutrophication of the Venice Lagoon (Sfriso et al., 1988).

While municipal and industrial pollution loads have been significantly reduced during the past decade by means of waste water treatment plants, nutrient loads from agriculture and animal rearing activities still remain a significant source of pollution, in particular because nitrogen has been shown to play a major role in the dystrophic cycle of the Lagoon (Bendoricchio et al., 1994; 1999) and its abatement is therefore of primary concern.

In the Lagoon Master Plan (Regione Veneto, 2000) the Regional Government has planned interventions and actions to reduce the pollutant loads from a total of $9,000 \mathrm{t}$ of nitrogen discharged in the average hydrologic year to a maximum of $3,000 \mathrm{t}$.

According to the estimate of the Master Plan 2000 , nitrogen from agricultural and animal farming sources accounts for about $65 \%$ of the nitrogen generated in VLW (around 9,000 tons on the average).

In 2002 the Regional Government has made available a substantial amount of financial resources for the implementation of agri-environmental measures in the VLW and issued a call for farmers' applications for the adoption of the practices supported by the measures (Del. n. 2116 2/08/2002). Farmers could apply for one or more of the measures listed in Table 1.

A great wealth of studies has been carried out in recent years on the VLW. Nevertheless, a comprehensive quantitative knowledge and an operational model allowing the estimation of the environmental benefits of the agri-environmental measures implemented is still lacking. On the other hand, monitoring activities are not suitable to assess the direct effects of the measures, as it is not practically feasible to measure the variations of nutrient releases from every single farm and track their fate along surface (and ground) water bodies, down to the final discharge to the lagoon.

Expert knowledge, acquired through adequate elicitation strategies and managed with robust and transparent methodologies, can help building a system of information that can be used to infer the effectiveness of agri-environmental measures, at least in comparative terms, if not in terms of quantitative absolute estimations.

\subsection{The evaluation context}

This section presents the results of the application of the NetSyMoD approach described above. The cognitive workshop for the evaluation of AESs was designed to manage the involvement of experts with different background and origin (farms, public administrations, universities) in an evaluation exercise to provide a preliminary assessment of the effectiveness and efficiency of the agri-environmental measures implemented in the VLW. Further research activities based on the use of nutrient balance sheets should provide a parallel, more traditional contribution to the evaluation of these measures.

The specific objective of the workshop was thus to involve a group of experts in the agro-

Table 1. Agri-environmental measures adopted in the VLW.

\begin{tabular}{cll}
\hline Measures & C.5.1.3a & $\begin{array}{l}\text { Description } \\
\text { Integrated agriculture, envisaging the implementation of 5-year crop rotations, with limits on } \\
\text { the surface area of maize, the adoption of a rational fertilisation plan, etc. }\end{array}$ \\
\cline { 2 - 3 } C5.1.3b & $\begin{array}{l}\text { Buffer strips and set aside, financing the plantation or maintenance of existing vegetated } \\
\text { buffer strips for 5 years, along field margins (5 to } 30 \mathrm{~m} \text { wide), or land set aside for 10 years. }\end{array}$ \\
\cline { 2 - 4 } C5.1.3c & $\begin{array}{l}\text { Rational irrigation and subsurface drainage, financing the substitution of low-efficiency grav- } \\
\text { itational systems with pressurised sprinkler irrigation and controlled tile drainage systems. }\end{array}$ \\
\hline C5.1.4 & $\begin{array}{l}\text { Investment on improved livestock rearing plant technologies, with various options, such as } \\
\text { new liquid manure storage tanks, improved feeding technologies, new machinery for liquid } \\
\text { manure distribution, etc. }\end{array}$ \\
\hline
\end{tabular}


environmental field in a participatory exercise to: - contribute to fill in the information gaps on mechanisms and environmental effectiveness of the policy measures adopted in the VLW for reducing nutrient loads reaching the lagoon;

- develop a scheme of the system under investigation, in which both the experimental evidence and the monitoring data could be contextualised within the assessment activities of local experts, for the benefit of the local government managing the agro-environmental policy.

At the roots of the methodology there is the belief, supported by multiple experiences at international level, that the involvement of experts and interested parties during the whole assessment process can contribute to overcome the frequent problems related to different visions and often conflicting interests in the management of environmental problems.

Local experts and the representatives of governing institutions, who have responsibilities for planning and management, are jointly involved in the process of developing conceptual models as a first, and mathematical simulations as a second step. The group setting facilitates the comprehension of such approaches and, as a consequence, their acceptance in the sphere of decisional and planning processes.

The main goal of the VLW application of the proposed methodology was to contribute to the adoption and correct use of information deriving from either models (conceptual and simulating models) or other sources, during the decisional processes in the agro-environmental field. Furthermore, the specific case study was designed to respond to the following problems:

- objective difficulty in analysing and tracing the complex cause-effect links among all the factors that determine the environmental effectiveness of different agri-environmental measures with respect to the ultimate objectives of the policies;

- plurality and diversity of agro-environmental schemes and objectives;

- lack of experimental monitoring data;

- lack of specific validated simulation models for the different environmental and productive situations of the Italian and European territory;

- problems in communication between the scientific community, policy makers and other interested parties.
In such context, a structured process for the involvement of experts and/or the wider public can contribute to improve the current situation by:

- creating a common and comprehensive vision of the problem, or rather of the agriculture-environment system in the VLW in this case, adopting a conceptual scheme that focuses on cause-effect links among the agricultural activities (crop and livestock productions), the environmental impacts and the measures of agro-environmental policy;

- evaluating the strength and weakness of the agro-environmental schemes adopted, with respect to the global process of policy implementation.

The exercise ultimately contributes to designing better - that is, more efficient and costeffective - agri-environmental schemes to reduce the pollution of the Venice Lagoon.

\subsection{The involvement of experts}

In order to select the experts to be involved in the workshop, a TFG was established, including a member of the research team, one representative of the Regional Environmental Protection Agency (potential user of the outcomes), one executive of the Agri-environmental Policy Department of the regional administration (competent for the AESs design), and a professional facilitator, in charge of adaptating the methodological framework to the case study and management of the CSM workshop.

The two representatives of the regional administrations identified the experts to be involved, who belong to the following three categories:

- administrators and officers of the local government;

- academicians with specific experience in the field in question;

- technicians, experts of the extension services, and farmers who adopted the AESs.

Starting with a preliminary short list of key experts, the snowball technique was then applied, whereby further suggestions were asked from people included in the first list, in particular with regard to the identification of technicians and farmers who have been involved in the application of the measures. The individuals identified through snowball sampling were then included in the group of the experts compiled by the TFG, and a final list of 24 people to be invited at the workshop was produced. A po- 
tential problem with the involvement of experts was that the assessment exercise had originated in the sphere of project research, and not within official institutional activities. This could have caused a lack of interest in the invited participants, who could have perceived their contribution as an academic exercise, rather than informing further decision-making. This critical aspect was dealt with during the organisation of the workshop, and it was clearly stated during the involvement of local actors. Nevertheless, the contribution of the experts was active and concrete, and the workshop can therefore be considered not simply an academic exercise, but a significant test.

\subsection{The CSM workshop}

The workshop consisted of two phases. The first phase concerned the framing of a mental model of the causal links between agricultural activities and the environment based on the DPSIR approach, with the use of brainstorming techniques such as the "Hodgson's hexagons" method (Hodgson, 1992); the second phase consisted of the evaluation exercise of the set of four measures, according to the approach proposed by Simos (1990).

Following the DPSIR approach, the ideas of the experts on the following issues were collected:

- identification of the causes and processes (Driving forces and Pressures) to be considered within the phenomena of agricultural diffuse pollution;

- identification of the effects of the production processes on the State of the environment and the Impacts (positive and negative) expected. The elaborated results are reported in the following pages, consisting in:

- processing of the data on causes and processes to select the elements configured as Driving forces (i.e. human activities directly or indirectly bound to VLW agriculture) and elements that can be included in Pressures (i.e. the processes and the mechanisms through which the Driving forces affect the state of the environment);

- clustering of the Driving forces and Pressures into relatively homogeneous groups within which to identify, according to the DPSIR approach, $D$ and $P$ categories/indicators at an upper synthesis level (see Tabb. 2 and 3);
Table 2. Driving forces.

\begin{tabular}{|c|c|}
\hline \multicolumn{2}{|c|}{ Agricultural driving forces } \\
\hline $\begin{array}{l}\text { Inspections and } \\
\text { sanctions }\end{array}$ & $\begin{array}{l}\text { - Sanctions } \\
\text { - Inspections and controls } \\
\text { - Corporate social responsibility } \\
\text { - Effluent disposal and control }\end{array}$ \\
\hline $\begin{array}{l}\text { Water management } \\
\text { and distribution }\end{array}$ & $\begin{array}{l}\text { - Rigid water distribution } \\
\text { system }\end{array}$ \\
\hline Animal productions & - Beef cattle breeding \\
\hline $\begin{array}{l}\text { Institutional and } \\
\text { normative context }\end{array}$ & $\begin{array}{l}\text { - Durability of the adopted } \\
\text { processes } \\
\text { - Bureaucracy and normative } \\
\text { changes } \\
\text { - Evolution of the CAP } \\
\text { - Institutional context } \\
\text { - Normative uncertainty }\end{array}$ \\
\hline $\begin{array}{l}\text { Public management } \\
\text { and planning }\end{array}$ & $\begin{array}{l}\text { - Lack of control by the Public } \\
\text { Administration } \\
\text { - Quality of services offered to } \\
\text { farmers } \\
\text { - Inaction of the Public Adminis- } \\
\text { tration } \\
\text { - Political support } \\
\text { - Planning and management } \\
\text { - Managerial approach }\end{array}$ \\
\hline Crop production & $\begin{array}{l}\text { - Field crops } \\
\text { - Crop mix }\end{array}$ \\
\hline $\begin{array}{l}\text { Political and social } \\
\text { role of agriculture }\end{array}$ & $\begin{array}{l}\text { - Union organisations and } \\
\text { political influence } \\
\text { - Labour force reduction } \\
\text { - Sectoral dynamics } \\
\text { - Redefinition of agriculture's } \\
\text { role, social expectations } \\
\text { - Ageing of farmers }\end{array}$ \\
\hline $\begin{array}{l}\text { Agricultural } \\
\text { structural aspects }\end{array}$ & $\begin{array}{l}\text { - Land values } \\
\text { - Urbanisation } \\
\text { - Number and size of holdings } \\
\text { - Organisation of the productive } \\
\text { process } \\
\text { - Agriculture vs. non-agriculture } \\
\text { land uses } \\
\text { - Farm typologies } \\
\text { - Role of contractors }\end{array}$ \\
\hline Economic context & $\begin{array}{l}\text { - Production costs and incentives } \\
\text { - Crop market and opportunities } \\
\text { - Economic performance of the } \\
\text { measures } \\
\text { - Costs of fertilisation } \\
\text { - Protein food costs } \\
\text { - Prices of agricultural commodities }\end{array}$ \\
\hline $\begin{array}{l}\text { Training, technical } \\
\text { assistance and } \\
\text { expertise }\end{array}$ & $\begin{array}{l}\text { - Knowledge of the nitrogen and } \\
\text { organic matter cycles } \\
\text { - Technicians' training } \\
\text { - Agro-meteorological services } \\
\text { - Part time agriculture and } \\
\text { know-how } \\
\text { - Farmers' behaviours } \\
\text { - Training and technical assistance } \\
\text { - Knowledge of the land }\end{array}$ \\
\hline
\end{tabular}


Table 3. Pressures.

\begin{tabular}{|c|c|}
\hline \multicolumn{2}{|c|}{ Pressures of agricultural origin } \\
\hline $\begin{array}{l}\text { Typology and } \\
\text { distribution of } \\
\text { cattle breeding }\end{array}$ & $\begin{array}{l}\text { - Nitrogen balance of animal } \\
\text { production } \\
\text { - Cattle breeding process } \\
\text { - Spatial distribution of cattle } \\
\text { breeding plants } \\
\text { - Wastewater volumes }\end{array}$ \\
\hline $\begin{array}{l}\text { Fertiliser } \\
\text { application } \\
\text { techniques } \\
\end{array}$ & $\begin{array}{l}\text { - Use of chemical fertilisers } \\
\text { - Nitrogen fertilisers' fractioning }\end{array}$ \\
\hline $\begin{array}{l}\text { Wastewater } \\
\text { management and } \\
\text { distribution }\end{array}$ & $\begin{array}{l}\text { - Wastewater releases } \\
\text { - Wastewater distribution } \\
\text { modality } \\
\text { - Adequate spreading surfaces for } \\
\text { liquid manures }\end{array}$ \\
\hline Cultivation systems & $\begin{array}{l}\text { - Nitrogen needs over time } \\
\text { - Winter cover crops } \\
\text { - Field crops vs. other agricultural } \\
\text { land uses } \\
\text { - Nitrogen crop balance }\end{array}$ \\
\hline $\begin{array}{l}\text { Technological } \\
\text { opportunities }\end{array}$ & $\begin{array}{l}\text { - Water treatment technologies } \\
\text { - Measuring technologies } \\
\text { - Technologies supporting the } \\
\text { farmer }\end{array}$ \\
\hline Irrigation systems & $\begin{array}{l}\text { - Irrigation technology } \\
\text { - Water balance } \\
\text { - Irrigation }\end{array}$ \\
\hline
\end{tabular}

- processing of the information on the State of the environment and the Impacts, in order to extract those elements that can be set as State indicators (i.e. those elements that identify the modalities through which the envi-
Table 4. State indicators.

\begin{tabular}{|c|c|}
\hline \multicolumn{2}{|c|}{ Effects on the state of the environment } \\
\hline $\begin{array}{l}\text { Effects on } \\
\text { landscape }\end{array}$ & - Landscape alteration \\
\hline $\begin{array}{l}\text { Effects on } \\
\text { groundwaters }\end{array}$ & $\begin{array}{l}\text { - Groundwater pollution } \\
\text { - Nitrates percolation }\end{array}$ \\
\hline $\begin{array}{l}\text { Effects on surface } \\
\text { waters }\end{array}$ & $\begin{array}{l}\text { - Alteration of surface hydrology } \\
\text { - Alteration of river quality status } \\
\text { - Nitrate concentrations } \\
\text { - Phosphate concentrations }\end{array}$ \\
\hline $\begin{array}{l}\text { Effects on water } \\
\text { resources } \\
\text { availability }\end{array}$ & - Water resources availability \\
\hline Effects on soil & $\begin{array}{l}\text { - Heavy metal concentrations } \\
\text { in the soil } \\
\text { - Erosion rate }\end{array}$ \\
\hline Effects on air & - Air quality \\
\hline
\end{tabular}

ronment can change under the effect of the Pressures in the VLW) and those that instead can be included in the Impacts (whereby evaluation concepts are expressed in positive or negative terms on the environmental state changes);

- Clustering of the State and Impacts indicators into relatively homogeneous groups, to identify the categories/indicators of $S$ and $I$ to an upper synthesis level (see Tabb. 4 and 5);

- Combination of synthesis indicators in a DPSIR global scheme for the analysis of agro-environmental issues in the VLW (see Fig. 4);

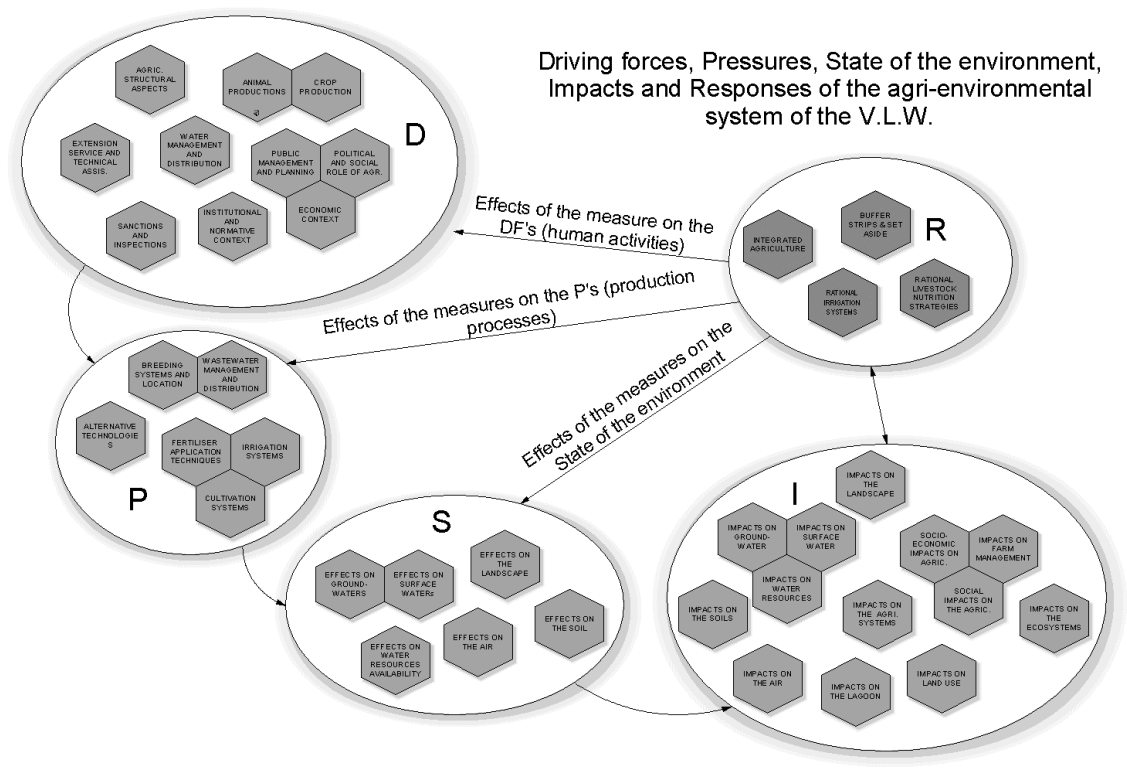

Figure 4. Organisation of synthesis indicators within the DPSIR scheme. 
Table 5. Impact indicators.

\begin{tabular}{|c|c|}
\hline \multicolumn{2}{|c|}{ Impacts on man and the environment } \\
\hline $\begin{array}{l}\text { Impacts on } \\
\text { agricultural systems }\end{array}$ & $\begin{array}{l}\text { - Consequences of reducing } \\
\text { animal production } \\
\text { - Liquid vs. solid manures } \\
\text { - Introduction of new technolo- } \\
\text { gies } \\
\text { - Re-distribution of slurry } \\
\text { - Variation of cropping systems } \\
\text { - Lower maize production } \\
\text { - Evolved technologies }\end{array}$ \\
\hline $\begin{array}{l}\text { Social impacts } \\
\text { on agriculture }\end{array}$ & $\begin{array}{l}\text { - Tangible benefits on the } \\
\text { community } \\
\text { - Loss of competitiveness } \\
\text { - Loss of cultural capital } \\
\text { - Increase of agriculture vs. non- } \\
\text { agriculture conflicts } \\
\text { - Reduction of within agriculture } \\
\text { conflicts } \\
\text { - Conflicts among farmers } \\
\text { - Positive environmental exter- } \\
\text { nalities }\end{array}$ \\
\hline $\begin{array}{l}\text { Impacts on farm } \\
\text { management }\end{array}$ & $\begin{array}{l}\text { - Increase of bureaucratic } \\
\text { burden }\end{array}$ \\
\hline Land use impacts & $\begin{array}{l}\text { - Agriculture vs. urban develop- } \\
\text { ment }\end{array}$ \\
\hline $\begin{array}{l}\text { Impacts on } \\
\text { ecosystem }\end{array}$ & $\begin{array}{l}\text { - Ecosystem evolution } \\
\text { - Low environmental benefits } \\
\text { - Biodiversity decrease } \\
\text { - Availability of water resources }\end{array}$ \\
\hline Impacts on soil & $\begin{array}{l}\text { - Loss of fertile soil } \\
\text { - Solutions of hydraulic problems } \\
\text { - Presence of wetlands }\end{array}$ \\
\hline $\begin{array}{l}\text { Impacts on water } \\
\text { resources }\end{array}$ & $\begin{array}{l}\text { - Potable water quality } \\
\text { - Water treatment costs }\end{array}$ \\
\hline $\begin{array}{l}\text { Impacts on the } \\
\text { lagoon }\end{array}$ & $\begin{array}{l}\text { - Algae bloom } \\
\text { - Lagoon eutrophication } \\
\text { - Recreational lagoon uses } \\
\text { - Quantity and quality of the } \\
\text { catch in the lagoon }\end{array}$ \\
\hline $\begin{array}{l}\text { Impacts on surface } \\
\text { water }\end{array}$ & - Rivers' degradation \\
\hline $\begin{array}{l}\text { Impacts on } \\
\text { deep water }\end{array}$ & $\begin{array}{l}\text { - Water table lowering } \\
\text { - Groundwater recharge }\end{array}$ \\
\hline $\begin{array}{l}\text { Impacts on the } \\
\text { landscape }\end{array}$ & $\begin{array}{l}\text { - Increased presence of } \\
\text { hedgerows } \\
\text { - Agricultural landscape quality }\end{array}$ \\
\hline Impacts on air & $\begin{array}{l}\text { - Greenhouse effects and the } \\
\text { Kyoto protocol }\end{array}$ \\
\hline
\end{tabular}

- Building of a so-called "recommendations list" with the hexagons not suitable to become part of the DPSIR scheme, but still representing issues, aspects to be considered or instances brought to the attention of the group by the experts (not reported here for brevity). Such interpretation seems to be confirmed by the fact that we are dealing with hexagons that originated at the end of the elicitation process.

\subsection{Comparative evaluation of four selected agro-environmental measures}

The evaluation of the effectiveness of environmental policies is a very challenging process, requiring analyses that very often are difficult to perform. For instance, in order to estimate the benefit of a specific agri-environmental measure, it is theoretically necessary to have two identical, or at least very similar, territorial situations where the values of the relevant environmental indicators can be assessed and compared, in presence and absence of the measures, over a sufficiently long - multiannual - time span. Rarely can assessors access such information, and therefore very often experts' knowledge is adopted to evaluate the effectiveness of policies, integrating it with all the available quantitative information resulting from monitoring and modelling.

Evaluation remains a complex process that must analyse and possibly quantify a series of factors such as the availability of financial resources, the mobilisation of human resources and the uptake by the interested people, etc., as reported in Figure 1. In practice a series of factors, analysed together and in sequence, can contribute to the comprehensive evaluation of the effectiveness of a specific measure resulting from an environmental policy. In particular agrienvironmental measures can be effective if:

- they are clearly referred to theoretically sound objectives;

- they are adequately supported with financial and administrative resources for their implementation;

- they are technically feasible;

- they significantly differ from ordinary techniques;

- the degree of uptake by the farmers is sufficient to obtain tangible/significant results;

- they are applied with adequate geographical targeting and distribution;

- they are properly monitored to avoid the risk that agreement holders may not comply with the management agreements. 
Having identified the above list of factors, in the second phase of the workshop an evaluation session was organised for the elicitation of experts' opinions within an evaluation framework, designed in order to apply MCA and thus derive a ranking of the alternative measures according to their perceived effectiveness.

The measures considered at the evaluation workshop are those described in Paragraph 4.1, and coded as follows:

A: Integrated agriculture

B: Buffer strips with trees

C: Improved irrigation systems (more efficient)

D: Improved livestock feeding systems.

The evaluation criteria according to the list of factors stated above are:

SA: Theoretical relevance with respect to the stated policy objectives

RF: Financial support and human resources made available by the competent administration

A: Degree of uptake by farmers

DG: Adequacy of geographical targeting and distribution

VP: Significance of differentiation from ordinary techniques

P: Technical feasibility

AC: Control feasibility.

According to Simos (Simos, 1990; Figueira et al., 2005), the procedure foresees the elicitation of weights through a ranking based on the use of cards. Every participant has a set of $n$ cards where the names of the options (or criteria) to be ranked (or weighted) are reported, plus a series of $m$ white cards to be used to express the separation between the judgments. In the present case cards have been replaced, for logistic reasons, with a series of $n$ $+m$ cells where the respondents were asked to place the code of the criterion or option. Participants could place on the same level (same cell of the matrix) more criteria/options believed to be of same importance/weight they could interpose one or more empty cells (i.e. white cards) between criteria/options with distinct judgments, to emphasise the diversity of the judgments.

Qualitative judgements expressed as described above are converted into quantitative values by first summing up the positions of the various options/criteria including the empty cells used, and then by dividing the rank of each option/criterion by the obtained sum.

The evaluation was carried out focusing at first on the analysis of the performance of the four options against each of the seven criteria (experts were to make a judgement as to how adequate the measures were in relation to each of the criteria, by filling the cells of a 7 by 4 columns matrix).

An evaluation matrix was produced (Criteria on the rows and Measures on the columns) by processing the 24 responses and averaging the judgements of the experts (Tab. 6).

Similarly, the experts were asked to express their opinions in terms of weights to be given to the seven criteria considered and the results are reported in Figure 5.

Interesting to note are both the average values of the weights and the variability of experts' judgements. Experts considered criterion SA (theoretical relevance with respect to the state policy objectives) as the most important, followed by RF (Financial support and human resources made available by the competent administration) and A (Degree of uptake of the measure by farmers). The first and the second

Table 6. Evaluation matrix, with scores and coefficients of variability of the judgements expressed by the experts.

\begin{tabular}{|c|c|c|c|c|c|c|c|c|}
\hline \multicolumn{9}{|c|}{ Measures } \\
\hline \multirow[t]{2}{*}{ Criteria } & \multicolumn{2}{|c|}{ A } & \multicolumn{2}{|c|}{ B } & \multicolumn{2}{|c|}{$\mathrm{C}$} & \multicolumn{2}{|c|}{$\mathrm{D}$} \\
\hline & Score & C.V. & Score & C.V. & Score & C.V. & Score & C.V. \\
\hline $\mathrm{Sa}$ & 0.387 & 47.7 & 0.260 & 64.2 & 0.213 & 71.8 & 0.140 & 41.9 \\
\hline $\mathrm{RF}$ & 0.276 & 46.4 & 0.253 & 46.9 & 0.262 & 67.9 & 0.209 & 61.1 \\
\hline A & 0.306 & 50.1 & 0.253 & 53.1 & 0.202 & 57.2 & 0.240 & 56.2 \\
\hline DG & 0.266 & 45.2 & 0.270 & 47.8 & 0.225 & 63.1 & 0.240 & 59.0 \\
\hline VP & 0.348 & 62.4 & 0.316 & 45.2 & 0.242 & 67.9 & 0.152 & 64.0 \\
\hline $\mathrm{P}$ & 0.210 & 61.8 & 0.293 & 49.5 & 0.287 & 56.7 & 0.211 & 69.7 \\
\hline $\mathrm{AC}$ & 0.112 & 72.4 & 0.477 & 28.6 & 0.249 & 40.2 & 0.162 & 87.3 \\
\hline
\end{tabular}




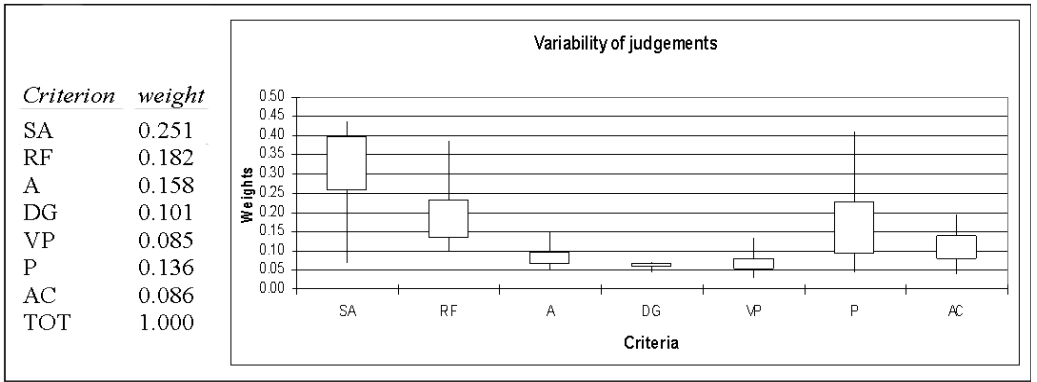

Figure 5. Results of the weighting of the evaluation criteria: average weights on the left in the table and box $\left(25^{\text {th }}\right.$ to $75^{\text {th }}$ percentiles $)$ and whiskers (min-max) plot of variability of experts' opinions on the right. criteria showed broader dispersion of judgements, while the third obtained a strong convergence of opinions, as the DG (Adequacy of geographical targeting and distribution) and VP (Significance of differentiation from ordinary techniques) criteria, but the latter have very low average weights.

In the final step, a weighted sum was performed by summing up the scores of the evaluation matrix weighted by the weight vector reported in Figure 5, with numerical results reported in Table 7. The experts involved in the evaluation process expressed a clear preference in terms of effectiveness for the first two measures (integrated agriculture and buffer strips), while considering the measure "reorganisation of irrigation systems" much less effective. Finally, experts' judgment indicates that interventions on livestock rearing systems are likely to be of limited effectiveness.

These results are of clear interest for the body financing agri-environmental schemes in

Table 7. Results of the multi-criteria analysis (MCA) of the four agri-environmental measures. Comparative effectiveness indices reported as final scores of the procedure.

\begin{tabular}{lcccc}
\hline \multicolumn{5}{c}{ Weighted scores } \\
\hline \multirow{5}{*}{ Criteria } & $\mathrm{A}$ & $\mathrm{B}$ & $\mathrm{C}$ & $\mathrm{D}$ \\
\cline { 2 - 5 } Sa & 0.097 & 0.065 & 0.054 & 0.035 \\
RF & 0.050 & 0.046 & 0.048 & 0.038 \\
A & 0.048 & 0.040 & 0.032 & 0.038 \\
DG & 0.027 & 0.027 & 0.023 & 0.024 \\
VP & 0.030 & 0.027 & 0.021 & 0.013 \\
P & 0.029 & 0.040 & 0.039 & 0.029 \\
AC & 0.010 & 0.041 & 0.021 & 0.014 \\
\hline \multicolumn{5}{c}{ Ranking } \\
\hline \multicolumn{5}{c}{ Measures } \\
Score & 0.290 & B 0.286 & 0.237 & 0.191 \\
\hline
\end{tabular}

the region, i.e. the Regional Administration: they provide not only a concise quantitative (even if with relative meaning) judgement, but also a systematic description of the motivations that brought the experts to obtain such results, i.e. the values reported in the first part of Table 7, where the weighted scores are reported. Moreover, according to the policy evaluation framework described in section 2.1, the final ranking scores (bottom of Tab. 7) assume the meaning of a comprehensive Comparative Effectiveness Index which can inform the future strategies in terms of agri-environmental measures to be included in the forthcoming rural development plans.

For instance, it is very interesting to note that option A (integrated agriculture) showed a remarkably better performance in terms of criterion SA (theoretical relevance) as compared to the other options, while the overall ranking shows a performance which is not much different from option B (buffer strips). The reason being the relatively bad performance of Option A for what concerns the feasibility of controls, which are clearly much easier for Option B, consisting in checking the presence of the vegetated buffer strips on the field, instead of analysing declarations of farmers in terms of techniques adopted, for instance in terms of fertilisers rates, as for Option A.

\section{Concluding remarks}

This paper reports the experimental application of a new participative method for the elicitation of experts' judgement in support of the evaluation of the environmental effectiveness of agrienvironmental measures.

The conceptual model developed in the first part of the workshop involving local experts in 
a group exercise is of general interest for depicting the physical and socio-economic system of the agriculture of the Venice Lagoon Watershed.

Monitoring activities aimed at acquiring experimental evidence of policy effectiveness could be framed within the agreed conceptual framework, but also mechanistic models, capable of simulating the diffuse pollution phenomena and the scenarios deriving from policy measures implementation, can use the DPSIR conceptualisation as a concise and effective communication interface.

In the present case study, parallel activities have been conducted for analysing the effectiveness of AESs, with a view to combine traditional methods based upon the nutrient balance sheets with participatory approaches to elicit experts' knowledge. Balance sheets may provide quantitative empirical assessment of the effectiveness in terms of relevance of the measures for the declared objectives of limiting the discharge of nutrients in the Venice Lagoon. They can also take into account the interaction between farming practice and environmental conditions and they can be weighted in terms of uptake rate by farmers in the various parts of the Venice Lagoon Watershed. In other words, traditional methods can provide empirical assessments of the theoretical relevance of criteria with respect to the stated policy objectives, degree of uptake by farmers, and adequacy of geographical targeting and distribution, excluding the other relevant criteria.

As for the results of the first part, which represent a useful communication framework also for other approaches, the outcomes of the second part (i.e. the participative MCA) can provide a framework for combining the outcomes of more traditional approaches (e.g. balance sheets) in a more comprehensive evaluation of policy effectiveness. Different and more sophisticated MCA decision rules could be considered to replace the weighted sum procedure used for this explorative application (e.g. other algorithms which are not completely compensatory), in case of application in an official evaluation process.

Even though the organisation of the workshop and in particular the contacts with the participants in order to ensure their participation required remarkable efforts during a period of approximately three weeks, we consider the amount of work and the results achieved in a half-day workshop quite remarkable.

The experience shows that in a situation of application in the real world one should preferably extend the workshop duration to the early afternoon, to allow more time for a series of checks on the consistency of the collected data. For instance, some experts provide answers that are in contrast with the most common opinions. In those cases the correct comprehension of the evaluation method should be double checked.

\section{Acknowledgements}

The authors gratefully thank the contribution of R. Camera, D. Castiglione, J. Mysiak, P. Terni, P. Parati, F. Zeni, who collaborated in the organisation and management of the participative workshop and the financial contributions of the European Commission, Project ITAES (SSPE-CT-2003-502070) and of the Environmental Protection Agency of the Veneto Region (ARPAV), Project AGeNDA.

\section{References}

Axelrod R. 1976. The structure of decision: The cognitive maps of political elite. Princeton University Press, Princeton, NJ.

Bendoricchio G., Coffaro G., De Marchi C. 1994. Trophic model for the Lagoon of Venice. Ecological Modelling, 75/76:485-496.

Bendoricchio G., Calligaro L., Carrer G.M. 1999. Consequences of diffuse pollution in the water quality of the Lagoon of Venice (Italy). Wat. Sci. Tech., 39, 3:113120.

CEC, 2000. Indicators for the integration of environmental concerns into the Common Agricultural Policy. Communication from the Commission to the Council and the European Parliament. COM(2000) 20 final.

Downs R.M., Stea D. 1973. Cognitive maps and spatial behaviour: process and products. In: Downs and Stea (eds.): Image and Environments. Aldine Publishing Company, Chicago. 15, 8-26.

Doyle J.K., Ford D.N. 1998. Mental models concepts for system dynamics research. Systems Dynamics Review, 14, 1:3-29.

EC (European Commission), 2003. EC Common Strategy for the Water Framework Directive (2000/60/EC). Guidance Document No. 8: Public participation in relation to the Water Framework Directive. Active Involvement, Consultation and Public Access Information. Office for the Official Publications of the European Communities, Luxembourg. 
EC, 2005. Common indicators for monitoring rural development programming 2000-2006. Commission Working Document D/761 FINAL: 01.2005.

Eden C. 1994. Cognitive mapping and problem structuring for system dynamics model building. System Dynamics Review, 10, 3/3:257-276.

EEA, 1999. Environmental indicators: typology and overview. European Environmental Agency, Copenhagen.

EEA, 2001. Reporting on environmental measures: are we being effective? EEA Report n. 25. European Environmental Agency, Copenhagen.

Figueira J., Mousseau V., Roy B. 2005. ELECTRE methods. In: Figueira J., Greco S. Ehrgott M. (eds.): Multiple criteria decision analysis: state of the art survey. Springer Verlag, 133-162.

Finn J., Kurz I. 2004. Measuring the environmental effectiveness of agri-environmental schemes: a short review and discussion of conceptual issues. TEAGASC.

Hwang Ch.L., Yoon K. 1981. Multiple attribute decision making: methods and applications, Springer Verlag, Berlin.

Hodgson A.M. 1992. Hexagons for systems thinking. European Journal of Operational Research, 59:220-230.

Huff A.S. 1990. Mapping strategic thought. John Wiley \& Sons, Chichester.

Kossoudji, 2001. Interest Groups and Organisations as Stakeholders. 35, Social Development Paper, World Bank, Washington DC.
OECD, 1997. Environmental indicators for agriculture. Organisation for Economic Co-operation and Development,, Paris.

Primdahl J., Peco B., Schramek J., Andersen E., Onate J.J. 2002. Environmental effects of agri-environmental schemes in Western Europe. Journal of Environmental Management, 67:129-138.

Regione Veneto, 2000. Piano Direttore 2000. Assessorato alle Politiche per il Territorio e Legge Speciale per Venezia.

Salganik M., Heckathorn D. 2004. Sampling and estimation in hidden populations using respondent-driven sampling. Sociological Methodology, 34:193-239.

Sfriso A., Marcomini A., Pavoni B., Orio A.A. 1988. Annual variations of nutrients in the lagoon of Venice. Marine Pollution Bulletin, 19, 2:54-60.

Simos J. 1990. Evaluer l'impact sur l'environment: Une appoche originale par l'analyse multicitere et la negociation. Presses Polytechniques et universitaries Romandes, Lausanne.

Varvasosovsvszky Z., Brugha R. 2000. How to do (or not to do)... a stakeholder analysis. Health Policy and Planning, 15:338-345.

Wasserman S., Faust K. 1994. Social network analysis: methods and applications. Cambridge University Press, New York.

Wetherell C., Plakans A., Wellman B. 1994. Social networks, kinships and community in Eastern Europe. Journal of Interdisciplinary History, 24:639-663. 
